\title{
Bromopyrrole Carboxamide Biosynthetic Products from the Caribbean Sponge Agelas dispar
}

\author{
Ivette C. Piña, ${ }^{\dagger \neq}{ }^{\ddagger}{ }^{*}$ Kimberly N. White, ${ }^{\dagger}$ Gustavo Cabrera, ${ }^{\ddagger}$ Eyleen Rivero ${ }^{\ddagger}$ and Phillip \\ Crews ${ }^{\dagger, *}$
}

Department of Chemistry and Biochemistry, University of California, Santa Cruz, California 95064, Centro de Química Orgánica, Escuela de Química, Facultad de Ciencias, Universidad Central de Venezuela, Apartado 47102, Caracas 1020AVenezuela.

\footnotetext{
* To whom correspondence should be addressed. I.C.P. Tel: 58-212-6051385, Fax: 58212-6051220,ipina@ciens.ucv.ve, P.C., Tel: 831-459-2603, Fax: 831-459-4197, phil@chemistry.ucsc.edu.

$\dagger$ Department of Chemistry and Biochemistry, University of California, Santa Cruz, California 95064.

* Centro de Química Orgánica, Escuela de Química, Facultad de Ciencias, Universidad Central de Venezuela, Apartado 47102, Caracas 1020A-Venezuela.
} 


\section{Supporting Information}

\section{Table of Contents:}

Figure S1. Underwater photo of Agelas dispar.

Table S1. Comparison of ${ }^{\mathbf{1 3}} \mathrm{C}$ NMR data of dibromoagelaspongin methyl ether (12) with values reported for dibromoagelaspongin (3).

Figure S2. ${ }^{1} \mathrm{H}$ NMR spectrum of dibromoagelaspongin methyl ether (12) at $500 \mathrm{MHz}$ (in $\mathrm{MeOH}-d_{4}$ )

Figure S3. ${ }^{13} \mathrm{C}$ NMR spectrum of dibromoagelaspongin methyl ether (12) at 125.7 $\mathrm{MHz}\left(\right.$ in $\left.\mathrm{MeOH}-d_{4}\right)$

Figure S4. g-HMBC NMR spectrum of dibromoagelaspongin methyl ether (12) at 500 $\mathrm{MHz}\left(\right.$ in $\mathrm{MeOH}-d_{4}$ )

Figure S5. Expansion of COSY NMR spectrum of dibromoagelaspongin methyl ether (12) at $500 \mathrm{MHz}$ (in $\left.\mathrm{MeOH}-d_{4}\right)$

Figure S6. Expansion of ${ }^{1} \mathrm{H}$ NMR spectrum of dispyrin (6) at $500 \mathrm{MHz}$ (in $\left.\mathrm{MeOH}-d_{4}\right)$

Figure S7. Expansion of ${ }^{1} \mathrm{H}$ NMR spectrum of dispyrin (6) at $500 \mathrm{MHz}$ (in $\left.\mathrm{MeOH}-d_{4}\right)$

Figure S8. ${ }^{13} \mathrm{C}$ NMR spectrum of dispyrin (6) at $125.7 \mathrm{MHz}$ (in $\mathrm{MeOH}-d_{4}$ )

Figure S9. Expansion of g-HMBC NMR spectrum of dispyrin (6) at $500 \mathrm{MHz}$ (in $\left.\mathrm{MeOH}-d_{4}\right)$

Figure S10. Expansion of g-HMBC NMR spectrum of dispyrin (6) at $500 \mathrm{MHz}$ (in $\left.\mathrm{MeOH}-d_{4}\right)$

Figure S11. Expansion of g-COSY NMR spectrum of dispyrin (6) at $500 \mathrm{MHz}$ (in $\left.\mathrm{MeOH}-d_{4}\right)$ 


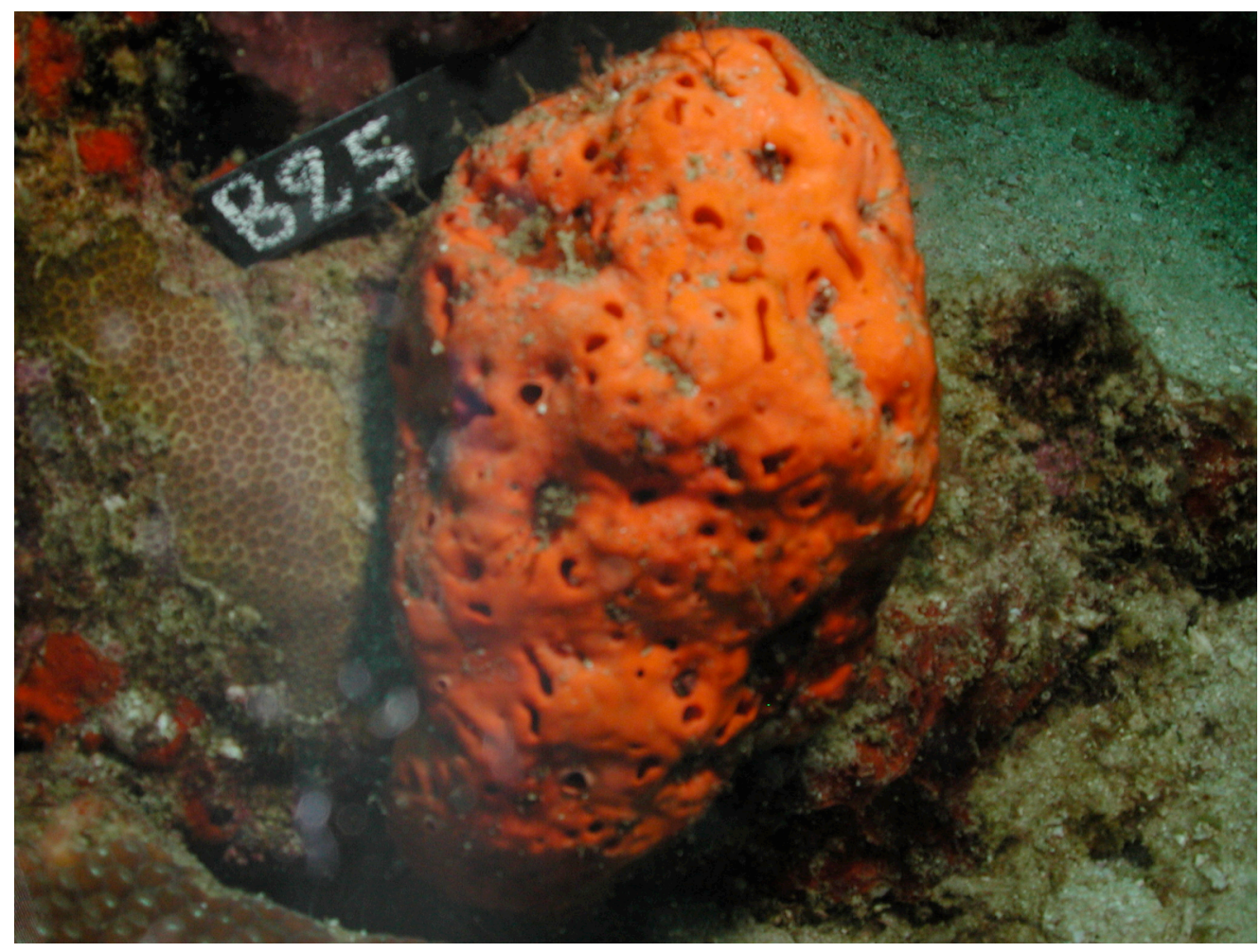

Figure 1. Underwater picture of Agelas dispar.

Table S1. Comparison of ${ }^{\mathbf{1 3}} \mathrm{C}$ NMR data of dibromoagelaspongin methyl ether (12) with values reported for dibromoagelaspongin (3). ${ }^{a}$

\begin{tabular}{lll} 
& $\begin{array}{l}{ }^{13} \mathrm{C} \text { NMR data for } \\
\text { dibromoagelaspongin methyl ether } \\
(\mathbf{1 2})\left(\mathrm{MeOH}-d_{4}\right)\end{array}$ & $\begin{array}{l}\text { Dibromoagelaspongin (3) literature } \\
\text { data }\left(\mathrm{DMSO}-d_{6}\right)^{a}\end{array}$ \\
\hline $\mathrm{C}-2$ & 127.9 & 126.9 \\
$\mathrm{C}-3$ & 110.6 & 108.5 \\
$\mathrm{C}-4$ & 105.7 & 103.8 \\
$\mathrm{C}-5$ & 106.4 & 104.1 \\
$\mathrm{C}-6$ & 94.3 & 91.7 \\
$\mathrm{C}-8$ & 158.8 & 156.4 \\
$\mathrm{C}-10$ & 92.8 & 89.8 \\
$\mathrm{C}-11$ & 29.8 & 33.2 \\
$\mathrm{C}-12$ & 17.4 & 16.7 \\
$\mathrm{C}-13$ & 37.4 & 35.6 \\
$\mathrm{C}-15$ & 159.3 & 156.6 \\
$\mathrm{C}-17$ & 51.8 & - \\
F Fedoreyev, S. A.; Ilyin, S. G.; Utkina, N. K.; Maximov, O. B.; Reshetnyak, M. V.; Antipin, M. Y.; \\
\multicolumn{2}{c}{ Struchkov, Y. T. Tetrahedron 1989, 45, 3487-3492. }
\end{tabular}




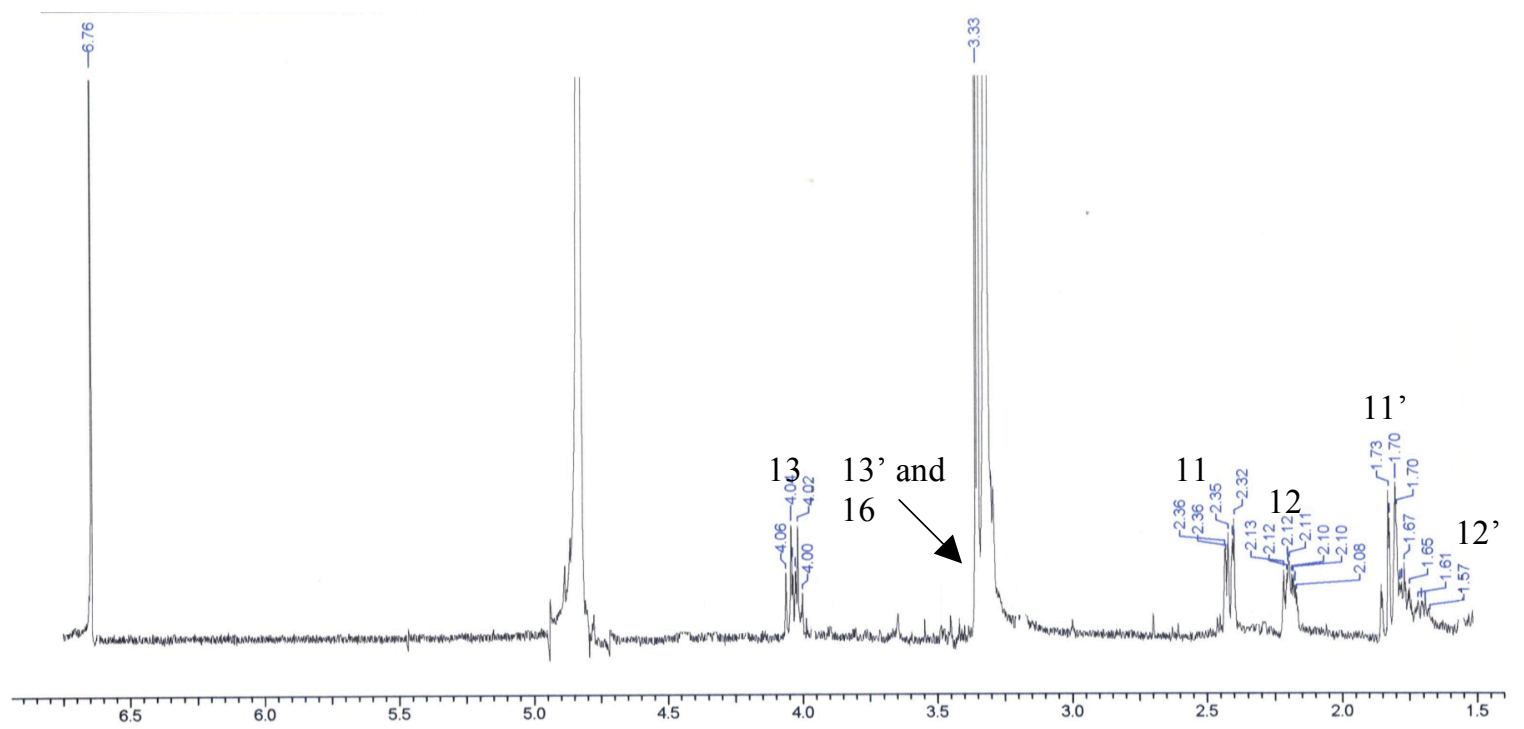

Figure S2. ${ }^{1} \mathrm{H}$ NMR spectrum of dibromoagelaspongin methyl ether (12) at $500 \mathrm{MHz}$ (in $\left.\mathrm{MeOH}-d_{4}\right)$.

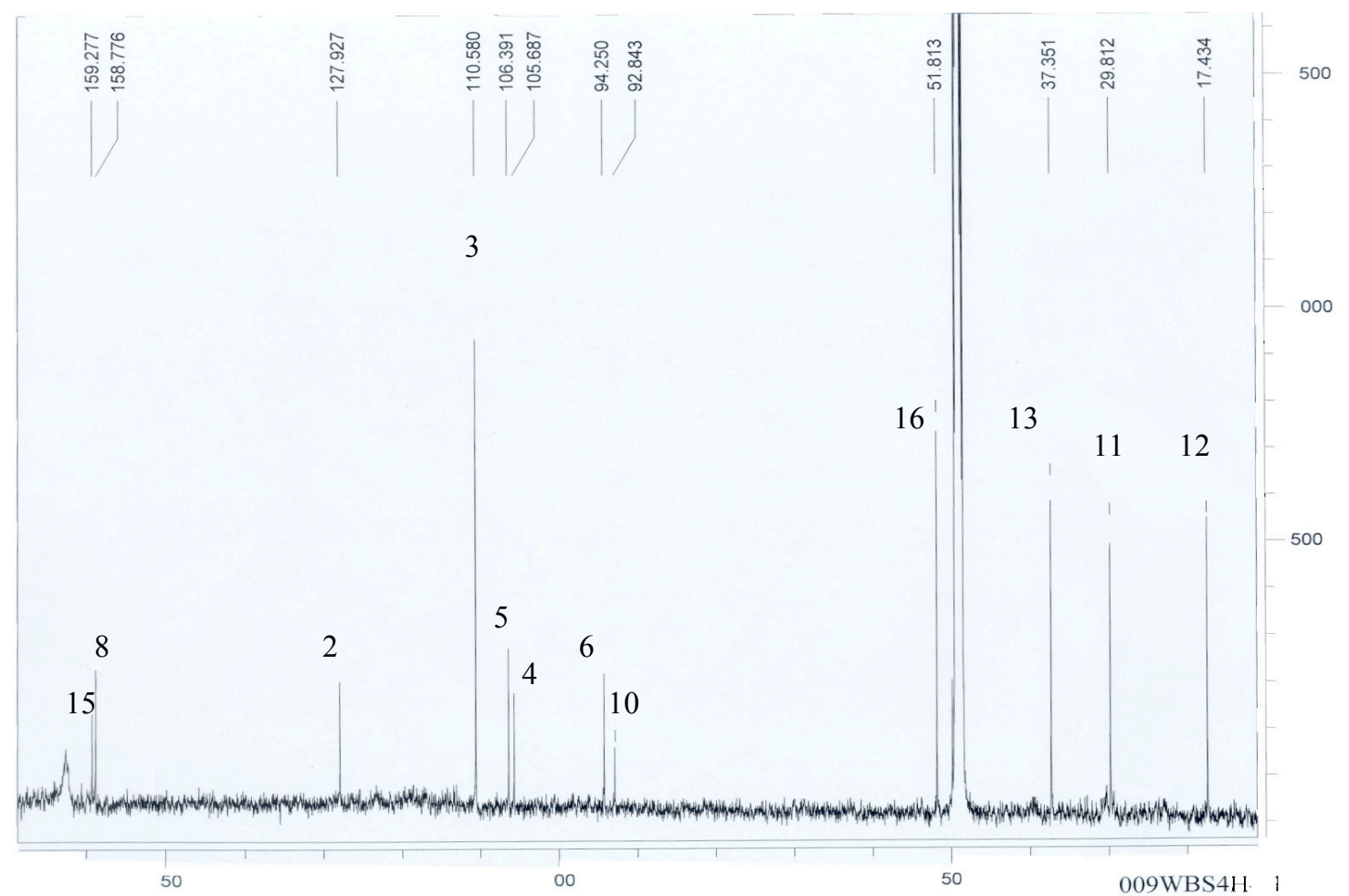

Figure S3. ${ }^{13} \mathrm{C}$ NMR spectrum of dibromoagelaspongin methyl ether (12) at $500 \mathrm{MHz}$ (in $\mathrm{MeOH}-d_{4}$ ). 


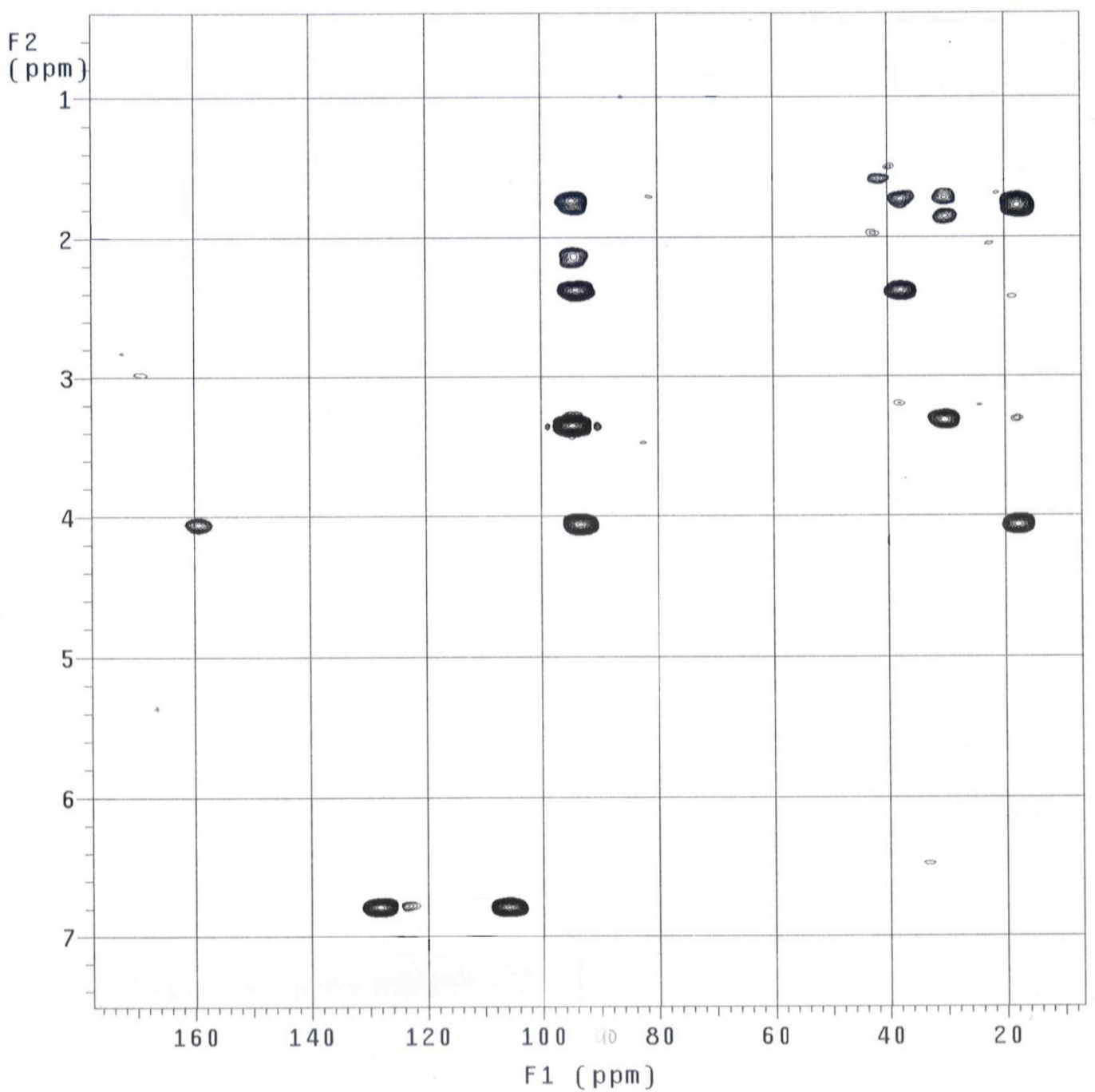

Figure S4. g-HMBC NMR spectrum of dibromoagelaspongin methyl ether (12) at 500 $\mathrm{MHz}$ (in $\mathrm{MeOH}-d_{4}$ ). 


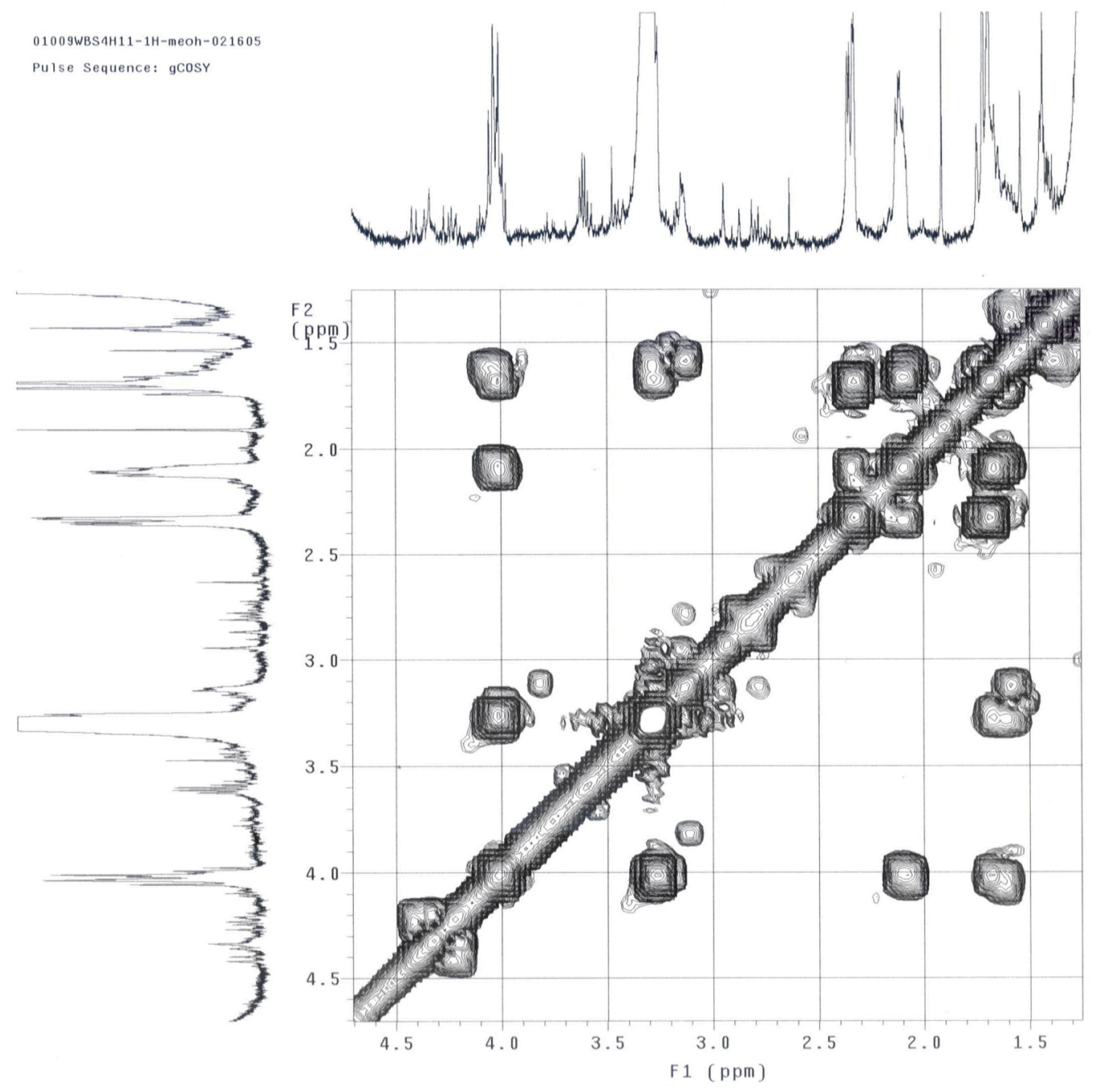

Figure S5. Expansion of g-COSY NMR spectrum of dibromoagelaspongin methyl ether (12) at $500 \mathrm{MHz}$ (in $\left.\mathrm{MeOH}-d_{4}\right)$. 


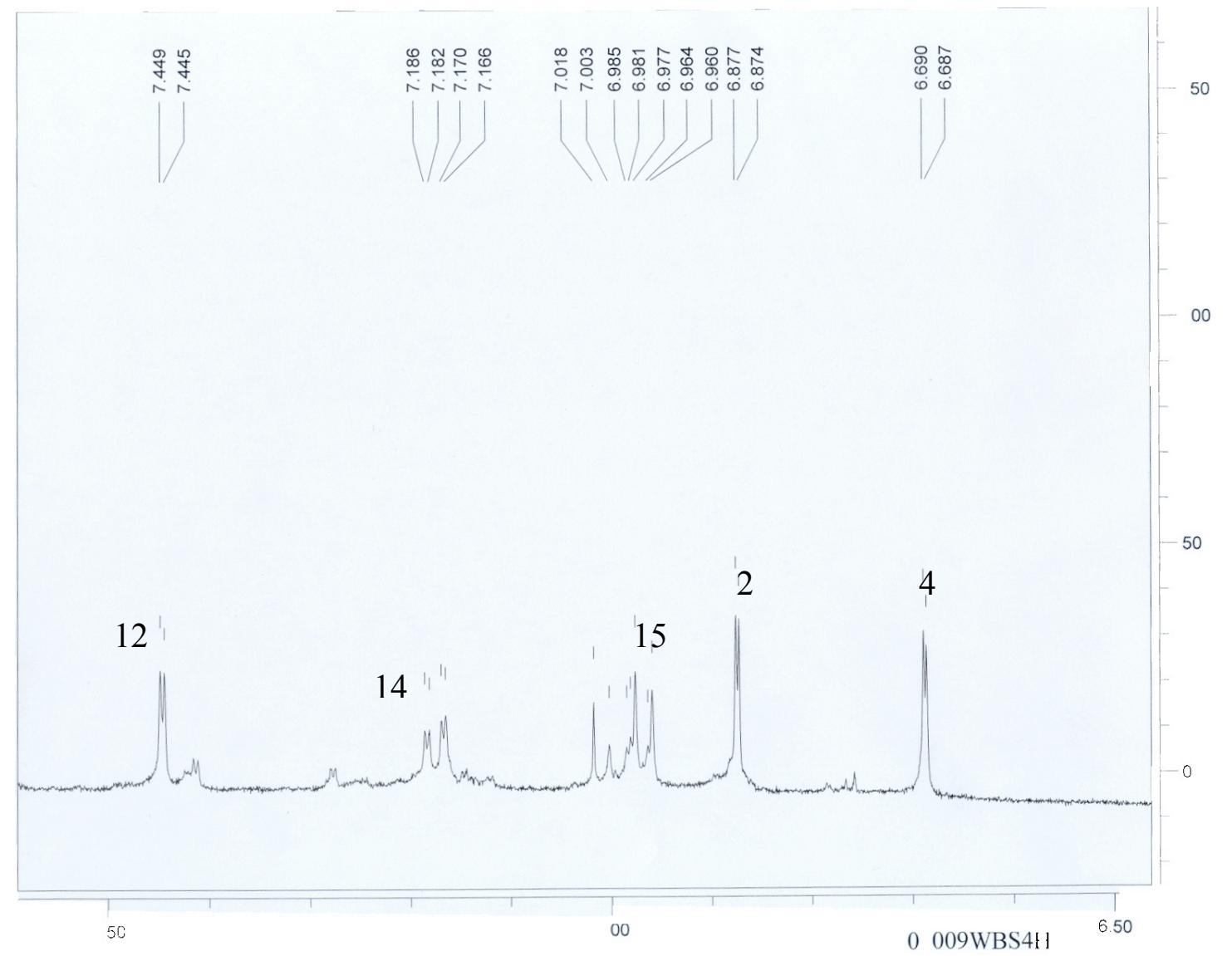

Figure S6. Expansion of ${ }^{1} \mathrm{H}$ NMR spectrum of dispyrin (6) at $500 \mathrm{MHz}$ (in $\mathrm{MeOH}-d_{4}$ ). 


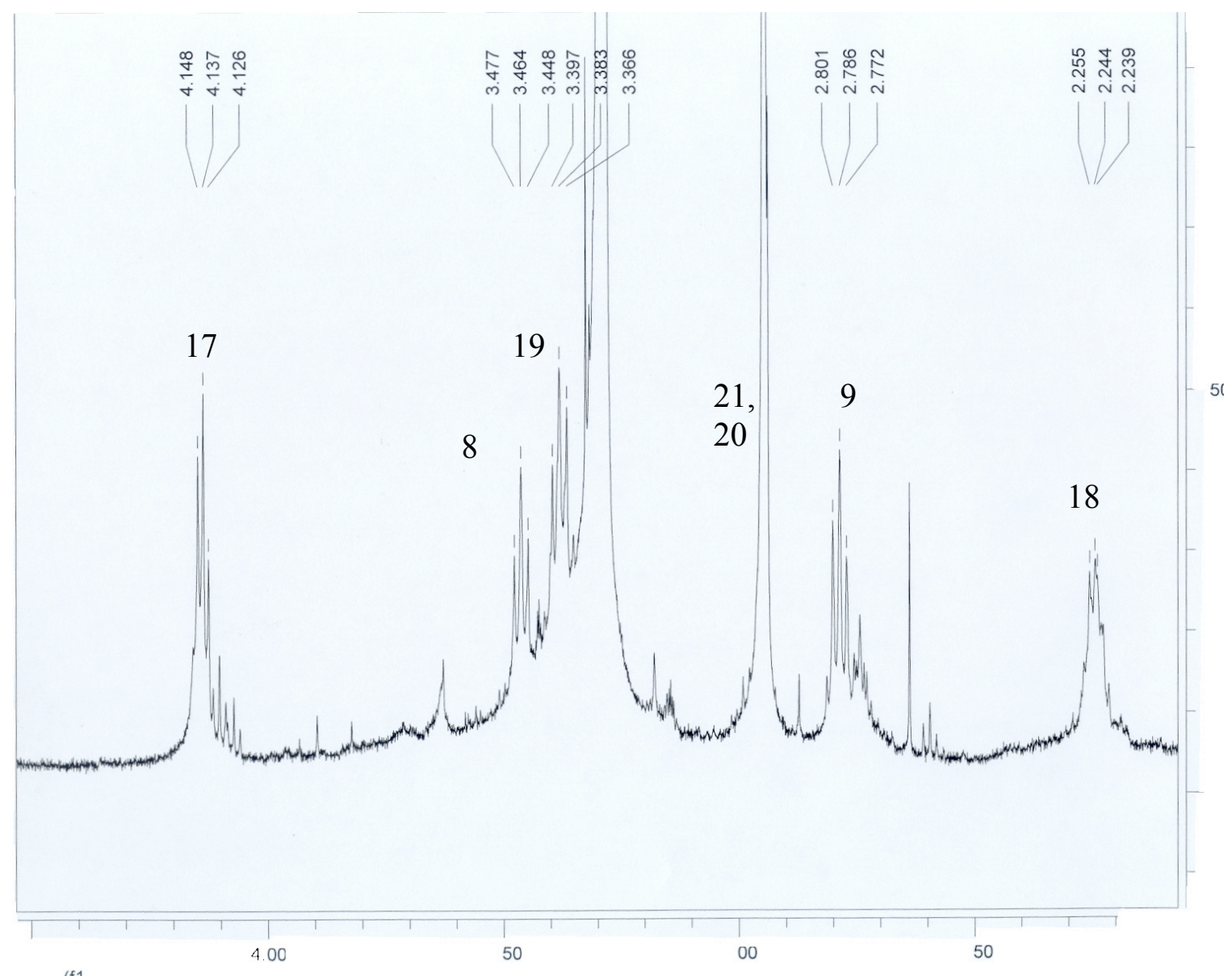

Figure S7. Expansion of ${ }^{1} \mathrm{H}$ NMR spectrum of dispyrin (6) at $500 \mathrm{MHz}$ (in $\mathrm{MeOH}-d_{4}$ ). 


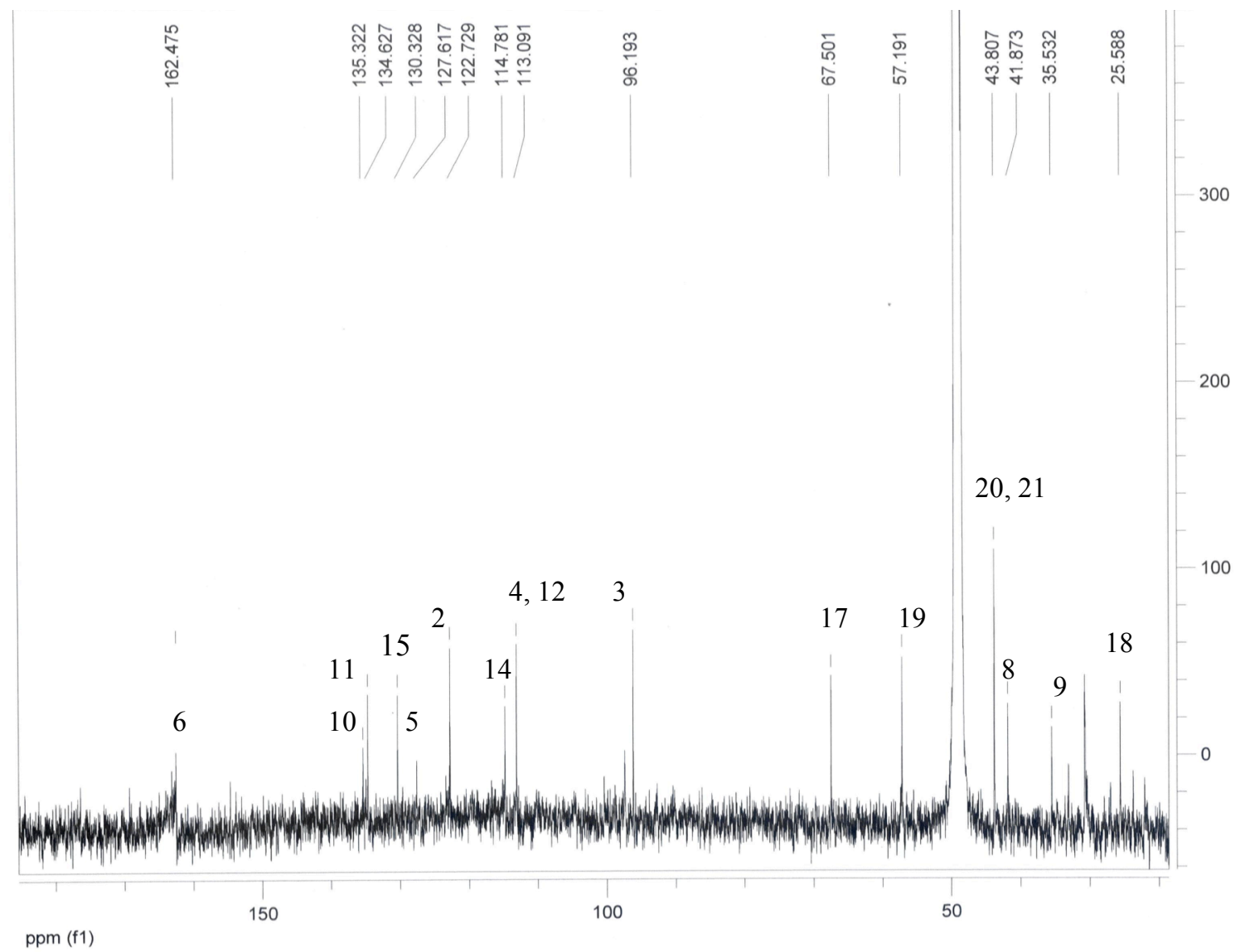

Figure S8. ${ }^{13} \mathrm{C}$ NMR spectrum of dispyrin (6) at $125.7 \mathrm{MHz}\left(\right.$ in $\left.\mathrm{MeOH}-d_{4}\right)$. 


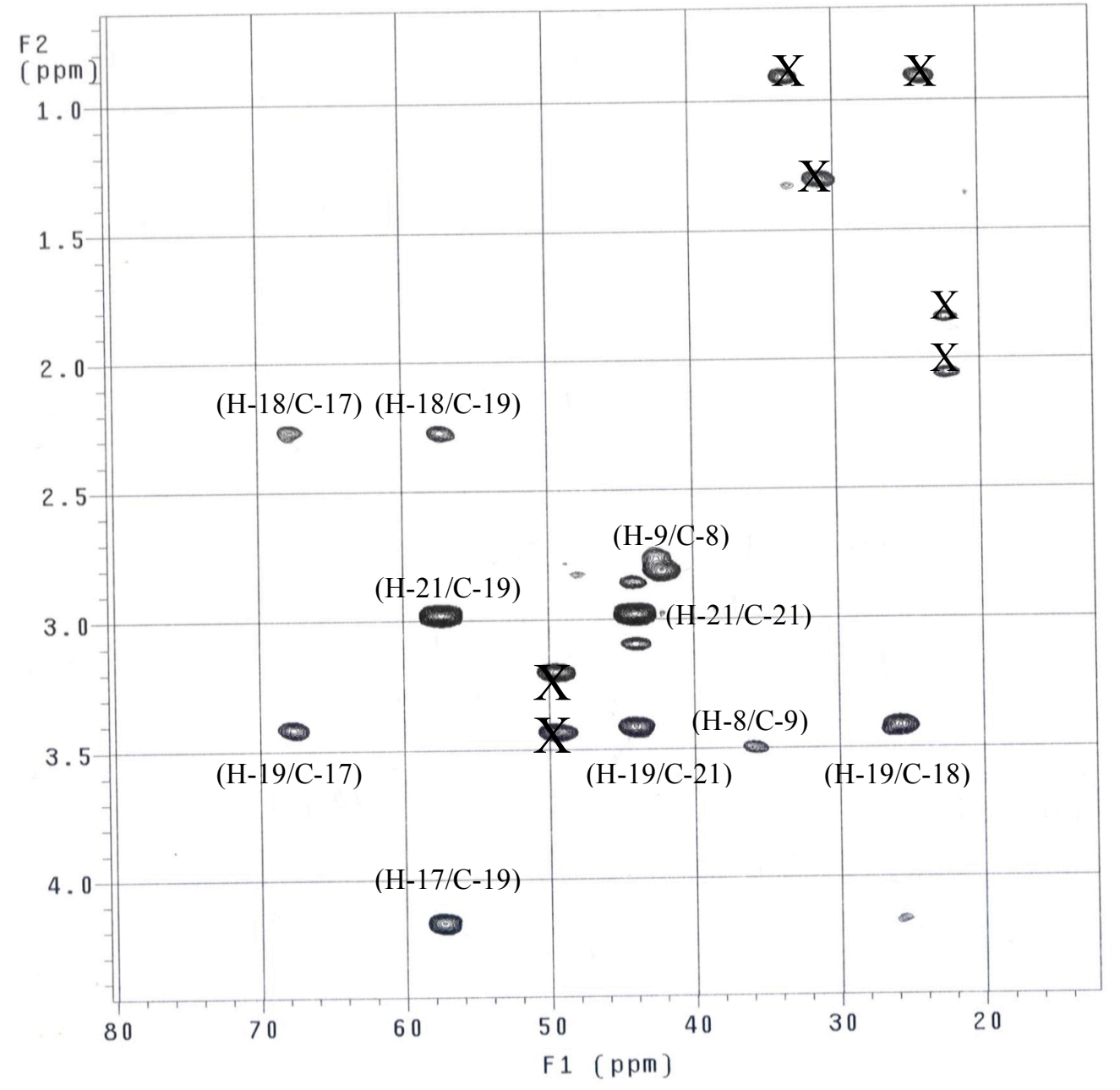

Figure S9. Expansion of g-HMBC NMR spectrum of dispyrin (6) at $500 \mathrm{MHz}$ (in $\left.\mathrm{MeOH}-d_{4}\right)$. 


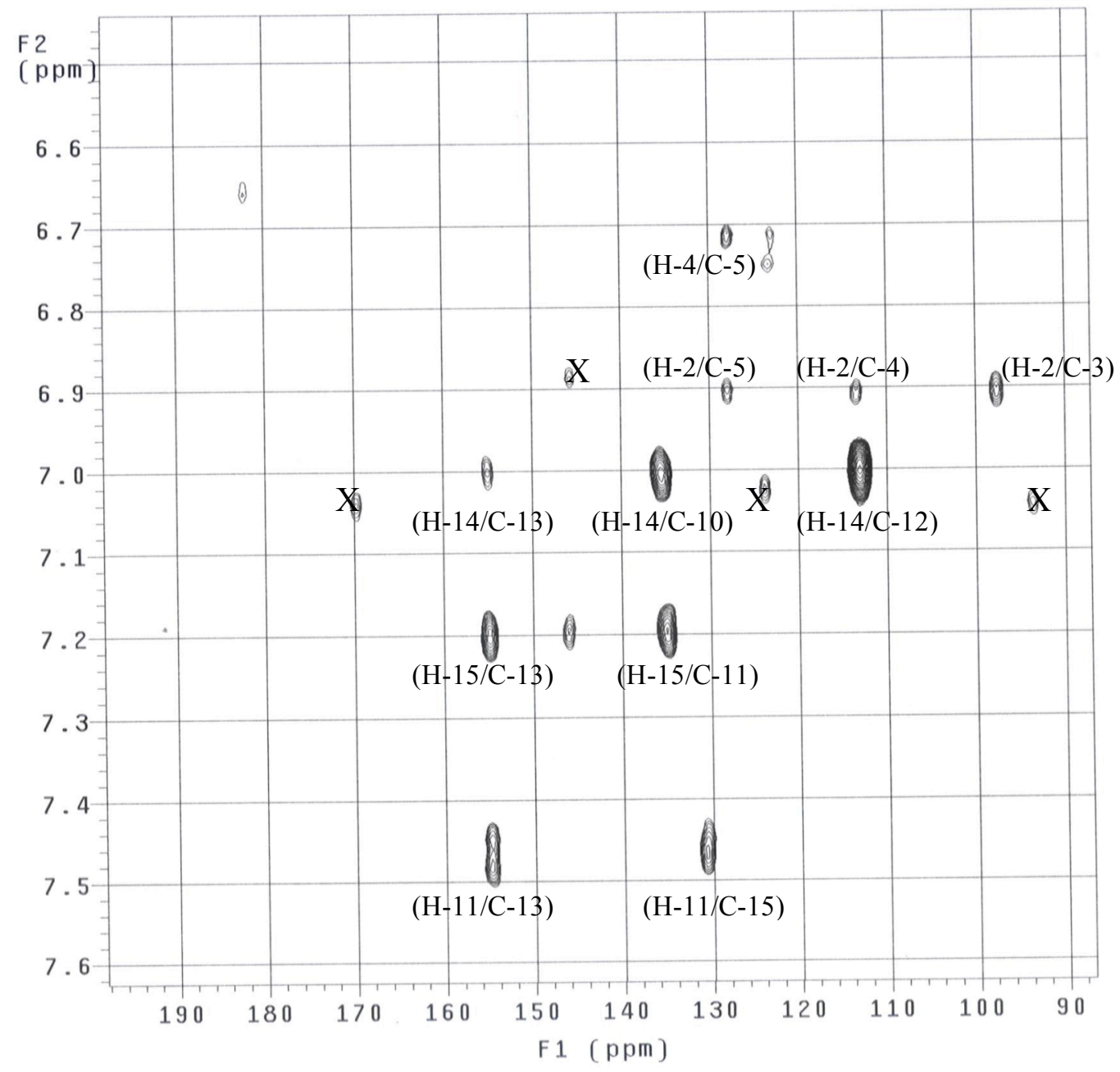

Figure S10. Expansion of g-HMBC NMR spectrum of dispyrin (6) at $500 \mathrm{MHz}$ (in $\left.\mathrm{MeOH}-d_{4}\right)$. 


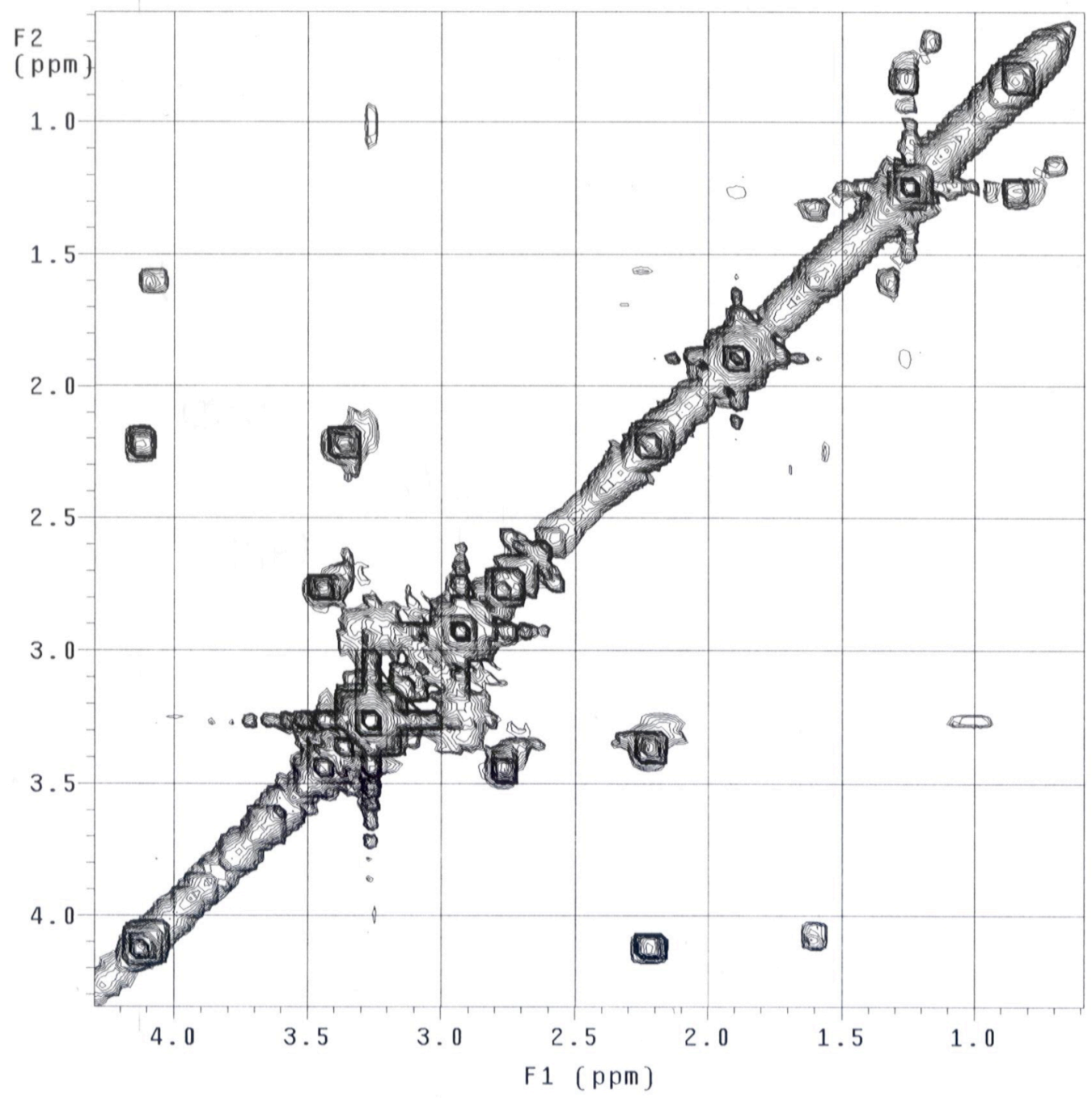

Figure S11. Expansion of COSY NMR spectrum of dispyrin (6) at $500 \mathrm{MHz}$ (in $\left.\mathrm{MeOH}-d_{4}\right)$. 